\title{
A FRAMEWORK FOR MANAGING A PORTFOLIO OF SOCIALlY RESPONSIBLE INVESTMENTS
}

\author{
Winfried Hallerbach, HaikUn Ning, \\ ALOY SOPPE, JAAP SPRONK
}

\begin{tabular}{|l|l|}
\hline \multicolumn{2}{|l|}{ ERIM REPORT SERIES RESEARCH IN MANAGEMENT } \\
\hline ERIM Report Series reference number & ERS-2002-54-F\&A \\
\hline Publication & May 2002 \\
\hline Number of pages & 21 \\
\hline Email address corresponding author & spronk@few.eur.nl \\
\hline URL Paper & http://www.eur.n/WebDOC/doc/erim/erimrs20020528160004.pdf \\
\hline Address & Erasmus Research Institute of Management (ERIM) \\
& Rotterdam School of Management / Faculteit Bedrijfskunde \\
& School of Economics \\
& Erasmus Universiteit Rotterdam \\
& P.O. Box 1738 \\
& 3000 DR Rotterdam, The Netherlands \\
& Phone: + 31 10 408 1182 / 4081282 \\
& Fax: + 31104089640 / 4526399 \\
& Email: info@erim.eur.nl \\
& Internet: www.erim.eur.nl \\
\hline
\end{tabular}

Bibliographic data and classifications of all the ERIM reports are also available on the ERIM website: www.erim.eur.nl 


\title{
ERASMUS RESEARCH INSTITUTE OF MANAGEMENT
}

\author{
REPORT SERIES \\ RESEARCH IN MANAGEMENT
}

\begin{tabular}{|c|c|c|}
\hline \multicolumn{3}{|c|}{ BIBLIOGRAPHIC DATA AND CLASSIFICATIONS } \\
\hline Abstract & \multicolumn{2}{|c|}{$\begin{array}{l}\text { In this paper we present and illustrate using reallife data a framework for managing an } \\
\text { investment portfolio in which the investment opportunities are described in terms of a set of } \\
\text { attributes and part of this set is intended to capture the effects on society. Here we link with the } \\
\text { emerging literature on SRl: Socially Responsible Investment. } \\
\text { Given the multivarious descriptions of the individual investment opportunities we show how } \\
\text { these can be cambined into portfolios with the same attributes at the portfolio level. Also we } \\
\text { show how a manager can systematically be supported in the choice between different portfolio } \\
\text { profiles. As part of the framework we use multi-criteria decision tools. }\end{array}$} \\
\hline \multirow{3}{*}{$\begin{array}{l}\text { Library of Congress } \\
\text { Classification } \\
\text { (LCC) }\end{array}$} & 5001-6182 & Business \\
\hline & 4001-4280.7 & Finance Management, Business Finance, Corporation Finance \\
\hline & HG 4229.5 & Portfolio management \\
\hline \multirow{3}{*}{$\begin{array}{l}\text { Journal of Economic } \\
\text { Literature } \\
\text { (JEL) }\end{array}$} & M & Business Administration and Business Economics \\
\hline & G 3 & Corporate Finance and Governance \\
\hline & G31 & Investment policy \\
\hline \multirow{3}{*}{$\begin{array}{l}\text { European Business Schools } \\
\text { Library Group } \\
\text { (EBSLG) }\end{array}$} & $85 \mathrm{~A}$ & Business General \\
\hline & $220 \mathrm{~A}$ & Financial Management \\
\hline & $220 \mathrm{P}$ & Investments, Portfolio management \\
\hline \multicolumn{3}{|c|}{ Gemeenschappelijke Onderwerpsontsluiting (GOO) } \\
\hline \multirow[t]{3}{*}{ Classification GOO } & 85.00 & Bedrijfskunde, Organisatiekunde: algemeen \\
\hline & 85.30 & Financieel management, financiering \\
\hline & 85.30 & Financieel management, financiering \\
\hline \multirow[t]{3}{*}{ Keywords GOO } & \multicolumn{2}{|c|}{ Bedrijfskunde / Bedrijfseconomie } \\
\hline & \multicolumn{2}{|c|}{ Financieel management, bedriffsinanciering, besliskunde } \\
\hline & \multicolumn{2}{|c|}{ Portfolio-analyse, Investeringen, Multicriteria analyse } \\
\hline Free keywords & \multicolumn{2}{|c|}{ Socially Responsible Investments, Portfolio management; Social responsibility, SRI } \\
\hline
\end{tabular}




\title{
A Framework for Managing a Portfolio of Socially Responsible Investments
}

\author{
Winfried Hallerbach, Haikun Ning, Aloy Soppe, Jaap Spronk ${ }^{\bowtie}$
}

\begin{abstract}
In this paper we present and illustrate using real-life data a framework for managing an investment portfolio in which the investment opportunities are described in terms of a set of attributes and part of this set is intended to capture the effects on society. Here we link with the emerging literature on SRI: Socially Responsible Investment. Given the multifarious descriptions of the individual investment opportunities we show how these can be combined into portfolios with the same attributes at the portfolio level. Also we show how a manager can systematically be supported in the choice between different portfolio profiles. As part of the framework we use multicriteria decision tools.
\end{abstract}

Rotterdam, May 2002

Erasmus University, P.O.Box 1738, 3000DR Rotterdam, The Netherlands

<hallerbach@few.eur.nl> <ning@few.eur.nl><soppe@few.eur.nl><spronk@few.eur.nl> 


\section{A Framework for Managing a Portfolio of Socially}

\section{Responsible Investments}

\section{Introduction}

Socially responsible investment is attracting more and more attention, both in practice and in academia. A growing number of fund managers do invest while taking account of the societal effects of the companies they are investing in. Although financial textbooks do not yet pay attention to socially responsible investments (SRI), the first articles do appear in the financial literature. One example is a special issue of the Journal of Banking and Finance (2002, forthcoming) on Managing Ethical Risk: How Investing in Ethics Adds Value. Another example is a recent article by Jensen (2001) in the Journal of Applied Corporate Finance in which he discusses the relation between Value Maximizing and Social Welfare. Opinions do differ widely. When focussing on the corporation some argue that the management should strive for the maximization of the financial value of the stocks of its current shareholders. Others add that under certain conditions this would lead to maximization of social welfare. A different view focuses on the need for the firm to take account of the interests of a variety of stakeholders other than the shareholders alone, in order to be able to maximize the value of the shares. One step further are those who argue that the firm has to deal with a dynamic goal complex in its own right (i.e. not as conditions for value maximization).

At this place we do not elaborate on the discussion what corporate firms should do. Instead, we concentrate on the role of investors trading in shares of these firms. In financial textbooks the standard assumption is that investors do have one objective only, being the maximization of their future expected wealth. Apparently, the practice of socially responsible investing shows that there are growing numbers of investors who want to take account of more objectives than future wealth alone. Because of the assumption of one objective only (although translated into the familiar bi-objective risk-return framework), the standard textbook solutions do provide only partly guidance to the socially responsible investor. 
Here we try to fill this gap by presenting and illustrating (using real-life data) a framework for managing an investment portfolio in which the investment opportunities are described in terms of a set of attributes and part of this set is intended to capture the effects on society. Given the multifarious descriptions of the individual investment opportunities we show how these can be combined into portfolios with the same attributes at the portfolio level. Also we show how a manager can systematically be supported in the choice between different portfolio profiles.

The overall framework is described in the next section. In Section 3 we describe the data reduction process, subsequently Section 4 focuses on the formulation of the portfolio model and Section 5 explains and illustrates the portfolio selection process. We conclude with a discussion on the potential use of our framework.

\section{Framework}

We start from the position of a socially responsible investor who wants to select a portfolio in which the social effects of the underlying firms are taken account of. This raises a series of problems. One of the first is how to define (and measure) the degree of social responsibility of individual investments. It is clear that there is not something like a social welfare function, which includes all social aspects and the trade-offs between them. On the contrary, each portfolio manager may have different views on what impacts on society are important, how to measure these impacts and how important they are relative to each other. However, we may assume that a long list of societal impacts can be defined from which an individual investor can select those that he or she finds important. In the practical application we will be referring to in the following sections, such a long list is indeed available. Another problem is how to combine the shares of different firms into a portfolio that best meets the preferences of the investor. In the application at hand there is a long list of social impacts for each of more than 400 individual stocks. Figure 1 summarizes how this highly complex problem can be structured. 


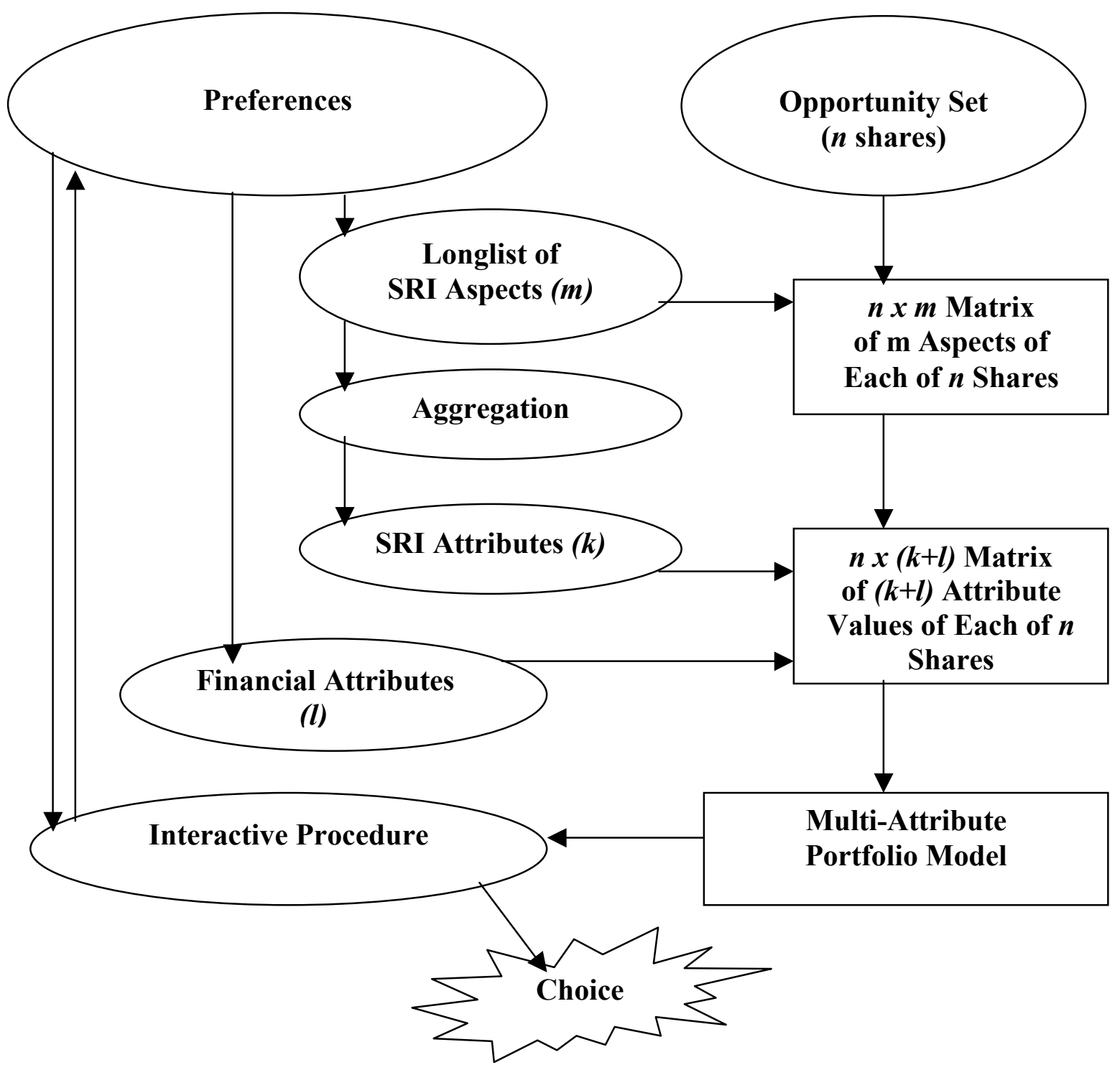

Our framework assumes that a firm's effect on society can be expressed and measured in terms of a series of characteristics (also labelled attributes). These characteristics have to be constructed through aggregation of different impacts in the long list and, in addition, are assumed to be relevant for the individual stock as well as for the portfolio level. For example, one could start with a list of environmental impacts of a company and combine these into an aggregate attribute that represents the overall environmental impact of the firm. Next the environmental impact of a portfolio of individual stocks can be defined as a weighted average of the impacts of the individual firms, where the weights are the fractions of the portfolio invested in each of the individual stocks. Subsequently, our framework supports the portfolio 
manager to find a balance between the different characteristics at the portfolio level. This is achieved by formulating a multi-attribute portfolio model in which the fractions invested in each of the individual stocks are instrumental variables, there is a budget constraint and possibly other constraints (depending on the specific problem setting; e.g. some investors are not allowed to invest more than $5 \%$ in a single stock) and there are $(\mathrm{k}+1)$ goal variables (the $\mathrm{k}+1$ attributes at portfolio level) to be maximized. Normally, these goal variables cannot be maximized simultaneously. Choices have to be made in one way or another. In our framework we propose to make these choices in a systematic and interactive manner. By interactive we mean that the manager who is responsible for the management of the portfolio can steer the portfolio selection process on basis of decisions that can be based on results and feedback generated on basis of earlier choices. The role of the manager is not limited to the process of finding compromises between the portfolio attributes. Also during the aggregation stage of the framework (i.e. aggregating the long list of SRI Aspects into a manageable set of SRI attributes) the manager has to make trade-off choices. The different stages of the framework will be discussed in the following sections while referring to an actual case in practice.

Two observations can be made. One is that the two stages of the framework, aggregation of aspects and the portfolio selection process, are like communicating vessels. One can put more emphasis on the aggregation stage, resulting in fewer attributes and thus a less complicated portfolio selection process. Alternatively, less aggregation will lead to a more complicated selection process. Another observation is that the choice for specific aggregation procedures and for a specific interactive procedure is not crucial for the use of the proposed framework. Depending on the specifics of a given SRI portfolio problem, also other aggregation tools and or other interactive procedures may be considered.

\section{From raw data to security attributes}

\subsection{Description of the data}

Our example dataset consist of quantitative scores on the sustainability performance of 273 European corporations of the FTSE-300 index and 166 US companies as quoted on respectively the London Stock Exchange and NASDAQ. The scores of these 439 companies are based on questionnaires gathered by the SiRi research group ${ }^{1}$ based on the year 2000 . On

\footnotetext{
${ }^{1} \mathrm{SiRi}$ is a cooperation of 12 European Social research companies (see appendix 1) that developed an identical research questionnaire for analysing companies. The sources of information for the analyst are: 1) companies
} 
top of the yes/ no answers of that research, the Triodos bank in the Netherlands developed a quantitative interpretation. They distinguished 6 stakeholder groups represented by 41 issues measuring a specific sustainability aspect of the company. The stakeholder groups distinguished are: Management, Customers, Vendors and Contractors, Employees, Environment and Community. In Table 1 we list all the attributes as distinguished per stakeholder group. Every attribute consists of four categories of questions: a) Public reports and communications, b) Principles and policies, c) Management systems and d) Impact and key data. Public reports and communication aim at measuring the degree of disclosure of information. Principles and policies represent the written results and communication of the companies' sustainability intentions. The questions on management systems address the organizational structure and the control of the sustainability intentions of the company. Finally, the impact and key data refer to the facts of the sustainable behaviour intentions as formulated in former questions. For example, in the latter category: Impact and Key data, the analyst checks whether the good intentions and management structures do or do not lead to public controversies regarding marketing, product safety and quality certification.

The entire score list is based on altogether 223 yes/no questions and some additional texts according to a fixed format for every analysed company. The numbers represent an ordinal scale where the percentage of the difference between the maximum and minimum score is calculated. For example a score of 40 indicates that a company reached $40 \%$ of the maximal sustainability score of 100 . The higher the score, the better the company satisfies the sustainability requirements of the SiRi analysts. ${ }^{2}$ In the next stages of data processing and portfolio optimization we assume that the scores are measured on an interval scale. Table 1 summarizes the attributes on sustainability.

Table 1: Sustainability attributes, scheduled per stakeholder group

\begin{tabular}{|l|l|l|}
\hline \multicolumn{1}{|c|}{ 1-CORP. GOVERNANCE } & \multicolumn{1}{|c|}{ 2-CUSTOMERS } & 3-VENDORS \& CONTRACTORS \\
\hline 8-Directors remuneration & 11-Product quality & 38-Principles \& Policies \\
\hline 9-Board structure & 12-Anti-trust & 39-Management \& organisation \\
\hline 10-Voting rights & 13-Marketing & 40-Impact contractors \\
\hline & 14-Customer satisfaction & 41-Reports \& communication \\
\hline
\end{tabular}

documents that are publicly released 2) national and international press articles 3) Associations, non-profit and non-governmental organizations and 4) contacts between SiRi group members and the company.

${ }^{2}$ If not all relevant information could be found or was not disclosed by the company, SiRi used two codes: NA (not available) and ND: not disclosed. NA is awarded if insufficient effort could be made by the analyst to answer a specific question. In the quantitative analysis the ND got zero points and the NA resulted in an average number for the company of the question involved. 


\begin{tabular}{|l|l|l|}
\hline \multicolumn{1}{|c|}{ 4-EMPLOYEES } & \multicolumn{1}{|c|}{ 5-ENVIRONMENT } & \multicolumn{1}{c|}{ 6-COMMUNITY } \\
\hline 15-Health \& safety & 28-Legislation \& damage & 1-Corruption \\
\hline 16-Discrimination & 29-Principles \& Policies & 2-Dictatorial regimes \\
\hline 17-Forced labour & 30-Management \& organisation & 3-Accounting \\
\hline 18-Child labour & 31-Genetic modification & 4-Tax \\
\hline 19-Unions/employee participation & 32-Reports \& communication & 5-Other legislation \\
\hline 20-Working hours & 33-Energy \& water use & 6-Community involvement \\
\hline 21-Compensation & 34-Emissions & 7-Beneficiary products \\
\hline 22-Labour legislation & 35-Waste \& recycling & \\
\hline 23-Reports \& communication & 36-Transport & \\
\hline 24-Management \& organization & 37-Product' impact on environment & \\
\hline 25-Financial participation & & \\
\hline 26-Personal circumstances & & \\
\hline 27-Training & & \\
\hline
\end{tabular}

The financial data are retrieved from Datastream International and represent yearly observations. Both the Total returns and the Book to market value concern the research period of the year 2000. Growth figures are calculated from end of year prices or accounting indicators.

\subsection{Data reduction process}

The first step was calculating the descriptive statistics. It turned out that 24 observations were invalid $(0.13 \%)$ and hence removed from the dataset. Next we eliminated all attributes that showed extremely skewed distributions. The lack of variability of these attributes was supposed to be uninformative for our problem setting. Following this procedure we eliminated 11 attributes. Table 2 represents the remaining attributes together with two financial variables: the Total return of the company and the Book to market value.

Table 2: Descriptive statistics of portfolio attributes.

Descriptive Statistics

\begin{tabular}{|c|c|c|c|c|c|}
\hline & $\mathrm{N}$ & Minimum & Maximum & Mean & Std. Deviation \\
\hline 1-Corruption & 438 & 25 & 100 & 77 & 13.8 \\
\hline 2-Dictatorial Regime & 439 & 0 & 100 & 74 & 18.1 \\
\hline 6-Community Involvement & 439 & 0 & 97 & 47 & 27.1 \\
\hline 8-Directors' Remuneration disclosure & 439 & 0 & 100 & 62 & 21.1 \\
\hline 9-Board Structure & 439 & 19 & 100 & 79 & 14.7 \\
\hline 11-Product Quality and Safety & 438 & 0 & 100 & 51 & 15.3 \\
\hline 14-Customer satisfaction & 439 & 0 & 100 & 40 & 20.1 \\
\hline 15-Health and Safety & 439 & 0 & 91 & 58 & 15.3 \\
\hline 16-Discrimination / Diversity & 437 & 27 & 100 & 68 & 19.7 \\
\hline 17-Forced Labour & 438 & 56 & 100 & 83 & 18.5 \\
\hline 18-Child Labour & 439 & 56 & 100 & 84 & 18.5 \\
\hline 19-Unions / Employee Participation & 435 & 0 & 100 & 65 & 14.9 \\
\hline
\end{tabular}




\begin{tabular}{|c|c|c|c|c|c|}
\hline 20-Working Hours & 439 & 22 & 100 & 83 & 18.9 \\
\hline 21-Compensation & 439 & 22 & 100 & 82 & 19.9 \\
\hline 23-Reports \& Comm. on Employees & 439 & 0 & 100 & 47 & 21.5 \\
\hline 24-Man. \& Organization on Employee & 439 & 0 & 100 & 54 & 19.8 \\
\hline 25-Financial Participation & 439 & 0 & 88 & 37 & 19.5 \\
\hline 26-Personal Circumstances & 439 & 0 & 100 & 49 & 26.7 \\
\hline 27-Training & 439 & 0 & 75 & 34 & 15.9 \\
\hline 29-Principles\&Policies on Environm. & 438 & 0 & 100 & 55 & 33.4 \\
\hline 30-Man. \& Organization Environment & 438 & 0 & 100 & 47 & 23.7 \\
\hline 32-Reports \& Comm. on Environment & 436 & 0 & 100 & 54 & 35.5 \\
\hline 33-Energy and Water Use & 439 & 0 & 100 & 19 & 22.4 \\
\hline 34-Emissions & 439 & 0 & 100 & 43 & 33.2 \\
\hline 35-Waste and Recycling & 439 & 0 & 100 & 46 & 25.1 \\
\hline 36-Transport & 437 & 0 & 100 & 47 & 34.2 \\
\hline 37-Products' Impact on Environment & 436 & 0 & 100 & 44 & 17.8 \\
\hline 38-Principles \&Policies on Contractors & 439 & 0 & 100 & 68 & 35.2 \\
\hline 39-Man. \&Organization Contractors & 437 & 0 & 100 & 70 & 33.3 \\
\hline 41-Reports \& Comm. on Contractors & 438 & 0 & 100 & 67 & 37.7 \\
\hline 42-Total return 2000 & 429 & -.89 & 3.96 & .062 & .43 \\
\hline 43- Book to Market Value 2000 & 403 & -1.54 & 100 & 0.68 & 5.2 \\
\hline
\end{tabular}

In order to reduce the number of variables further we aggregated attributes by using cluster analysis in combination with factor analysis. The remaining attributes were clustered conform the stakeholder approach. Because of the substantial number of attributes related to employee relations, this stakeholder group was split up into three different subgroups. Table 3 summarizes the remaining factors and the corresponding attributes. A factor is calculated as the un-weighted average value of the attributes involved.

Table 3: Factors implemented in the portfolio optimisation.

\begin{tabular}{|l|l|c|c|}
\hline \multicolumn{1}{|c|}{ Factor name } & \multicolumn{1}{|c|}{$\begin{array}{c}\text { Attributes involved } \\
\mathrm{nr}:\end{array}$} & $\begin{array}{c}\text { Mean } \\
\text { score }\end{array}$ & $\begin{array}{c}\text { Standard } \\
\text { deviation }\end{array}$ \\
\hline 1-Community & $1,2,6$ & 66 & 13.8 \\
\hline 2-Corporate governance & 8,9 & 70 & 15.3 \\
\hline 3-Customer relations & 11,14 & 46 & 16.8 \\
\hline 4-Employee: contractual relations & $17,18,20,21,38,39,41$ & 77 & 22.4 \\
\hline 5-Employee: Labour rights & 15,1619 & 64 & 12.7 \\
\hline 6-Employee: Labour care & $23,24,25,26,27$ & 44 & 13.3 \\
\hline 7-Environment: Principles \& Policies . & $29,30,32$ & 52 & 27.1 \\
\hline 8-Environment: Facts \& results & $33,34,35,36,37$ & 40 & 17.1 \\
\hline 9-Total return & 42 & $6.2 \%$ & $43.3 \%$ \\
\hline 10-Book to market value & 43 & 0.68 & 5.2 \\
\hline
\end{tabular}

The ten resulting factors of table 3 are used as input for the multi- attribute portfolio procedure. 


\section{The multi-attribute portfolio approach}

The traditional Markowitz (1959) approach to portfolio selection assumes that the opportunity set of securities can be fully characterized by the joint distribution of their returns. More specifically it is assumed that the probability distribution of the portfolio return can be fully described by means of its locus and its shape, measured by the mean and the variance. Experiences from practice, however, reveal that not all relevant information is captured by these two explicit return and risk attributes. In this section we first discuss the choice of characteristics that describe the securities in the opportunity set. Next we discuss the selection of a portfolio on the basis of this information.

\subsection{Multi-attribute representation of securities}

Various extensions to the mean-variance model were proposed. The uni-dimensional risk measure variance, for example, can be replaced by a set of multi-dimensional risk measures. These risk measures comprise higher order statistical moments of the return distributions, or are based on a multi-factor risk model (see Elton \& Gruber (1995), e.g.). Other attributes can be considered important because they represent 'anomalies ${ }^{3}$. For common stocks, 'firm size' is a long-time notorious variable. Other examples are price ratios as indicators for fundamental firm value like earnings/price, book/price (book value of common equity per share divided by market price per share), cash flow/price, sales/price and dividend/price. In the context of 'value investing' there is great-renewed interest in these long time familiar attributes ${ }^{4}$.

In the view of (descriptive) financial theory, an attribute's ability to contribute to the explanation of cross-sectional return differences appears to be a convincing criterion for the selection of relevant attributes. An attribute will only carry a significant premium when it is 'priced' in the market. However, a non-average investor can face a set of investment opportunities that is different from the market (i.e. the average investor). Hence this investor is only interested in the relevance of this attribute in his opportunity set. Furthermore, partly connected to the former argument, the reward that an investor attaches to the exposure to an

\footnotetext{
${ }^{3}$ An attribute is an anomaly with respect to an asset pricing theory when that attribute possesses power to explain cross-sectional variation in expected returns in addition to the risk measures as specified by the pricing model at hand. An attribute is an anomaly with respect to the efficient market hypothesis when it can be used to forecast future returns. Detailed overviews are provided by Fama (1991) and Hawawini \& Keim (1995).
} 
attribute (a 'subjective' premium) may well be different from the premium that the market as a whole attaches to that attribute (the 'objective' premium). So despite the official view of general financial theory, there may well exist security attributes that are relevant because of idiosyncrasies in the investor's personal decision context. In this case, the incorporation of additional attributes can be motivated from the specific tastes and desires of the investor, from specific investment constraints he faces, or from distinctive characteristics of the investment alternatives. In the framework of this paper one naturally thinks of sustainability performance characteristics as discussed in section three. In short, it is up to the investor to decide which variety of attributes helps to decide between the various securities.

The formulation of a multi-attribute representation of securities as outlined above is the first stage in a general framework for portfolio analysis and selection, as proposed by Hallerbach \& Spronk [1997]. This stage comprises a detailed and investor-specific security analysis. Preference information is used to demarcate the set of $\mathrm{k}$ attributes that an investor considers important. For the investor, a financial security then represents a basket of, say, k attributes and can fully be characterized by a k-tuple of attribute scores. In this view, when buying a security, an investor is actually buying an exposure to various attributes. The selection of relevant attributes is no 'once and for all' activity. The investor's decision context and the securities' economic environment may change over time and may become 'better understood' because of 'learning effects'. As a result, the set of relevant attributes may change over time.

The second stage of the framework is the analysis of feasible portfolios and the selection of a final portfolio. The issue of multi-attribute portfolio selection is to balance the attributes of the individual securities on the portfolio level. That is, given the security attributes and the investor's profile (personal context), the attributes of his portfolio must be fashioned in a way that suits his particular circumstances and preferences best. This stage is discussed in more detail below.

\subsection{Choosing between attribute exposures}

The step from securities to their representation in terms of attribute scores can be justified by referring to consumer theory, where 'characteristics models' have been developed for

\footnotetext{
${ }^{4}$ Seminal papers on value investing are Fama \& French $(1992,1993)$ and Lakonishok, Schleifer \& Vishny (1994).
} 
describing consumer behaviour. In this respect we especially note Lancaster (1966, p.133), whose contribution is "breaking away from the traditional approach that goods are the direct objects of utility and, instead, supposing that it is the properties or characteristics of the goods from which utility is derived"5. These implied characteristics models opened the way for a theory of multi-attribute choice. Transposed to the investment decision, we can assume that investors buy securities for the attributes they offer and that different securities are essentially different packages of attributes. Hence, we can specify a mapping of the securities in the space spanned by the attributes:

$$
\text { security } \mathrm{i} \rightarrow\left\{\mathrm{a}_{\mathrm{i} 1}, \mathrm{a}_{\mathrm{i} 2}, \ldots, \mathrm{a}_{\mathrm{ij}}, \ldots, \mathrm{a}_{\mathrm{ik}}\right\} \quad, \mathrm{i} \in \mathrm{N}
$$

where $a_{i j}$ is the value that attribute $j$ takes for security $i$. Likewise, when composing a portfolio, the investor is actually composing an appropriate portfolio exposure to the various attributes:

$$
\text { portfolio } \mathrm{p} \rightarrow\left\{\mathrm{a}_{\mathrm{p} 1}, \mathrm{a}_{\mathrm{p} 2}, \ldots, \mathrm{a}_{\mathrm{pj}}, \ldots, \mathrm{a}_{\mathrm{pk}}\right\}
$$

Hence, an investor's preference functional is directly specified in the multi-dimensional terms of relevant security attributes. For a given portfolio, its exposure to a certain attribute can be calculated as a weighted average of the attribute exposures of the individual securities contained in this portfolio. The fractions invested in each of these securities can thus be treated as instrumental variables. Therefore, the attribute exposures can be seen as goal variables that are linear in the portfolio holdings ${ }^{6}$. Often, the investor will try to either minimize or maximize each of these goal variables. Alternatively, the investor may strive to attain a target level or desired score on some attribute(s). Depending on the investor's insights and preferences, the relative importance of each of these goals may vary. Generally, no portfolio can be found for which each of the goal variables reaches its optimal value or for which all criteria are met. As a consequence, the investor has to evaluate the trade-offs between the various goal variables.

\footnotetext{
${ }^{5}$ For a discussion and review of characteristics models, we refer to Deaton \& Muellbauer (1980).

${ }^{6}$ Some attributes can cause problems. For example, individual securities' price/earnings and market-to-book ratios must be aggregated in harmonic form in order to obtain portfolio value ratios. It is then simpler to consider the securities' earnings/price and book-to-market ratios, which can be aggregated in a linear fashion to a portfolio ratios.
} 
There are several routes leading to the selection of a portfolio, depending on the amount of information available on the investor's preference structure. Assuming a large amount of preference information, the traditional utility framework could be extended to a multidimensional context by casting a utility function in terms of multiple portfolio attributes. Consequently, the mean-variance preference functional $\mathrm{Z}\left(\mathrm{Ep}, \sigma^{2} \mathrm{p}\right)$ is replaced by a 'Lancaster (1966)-type' of function $\mathrm{Z}\left(\mathrm{a}_{\mathrm{p} 1}, \ldots, \mathrm{a}_{\mathrm{pk}}\right)$. In that case, an explicit optimisation problem can be formulated and solved. Unfortunately, the complexity of specifying a multi-attribute preference functional is enormous and not likely to be overcome in practice. In multi-attribute utility theory, this complexity is reduced by assuming (strong) separability of the preferences. When this assumption is satisfied, a series of uni-dimensional (i.e. single attribute) utility functions can be assessed, where after these component functions are combined (in a linear, multiplicative or other fashion), using information about attribute trade-offs. In this way, the exposures are evaluated attribute by attribute and then combined to obtain an overall measure of desirability. Still, this places a heavy information burden on the investor. The problem here is to ex ante specify the uni-dimensional preferences for each of the attributes as well as the overall preference functional that incorporates the evaluation of a combination of attribute exposures and their trade-offs.

Another route is to cast the multi-dimensional preference functional in the form of a (linear) programming model. One way is to maximize the portfolio's exposure to one attribute (expected return, e.g.) subject to restrictions on the other attribute scores. ${ }^{7}$ The problem with such a specification is that it is intrinsically uni-dimensional: only one attribute is optimised, while the other attributes only serve as constraints. Another way to extend the linear programming formulation to a multi-dimensional context is to use a weighted average of the various attributes as the objective function ${ }^{8}$. A linear programming formulation like this can only be employed when the trade-offs between the attributes can be specified properly.

In formulating priorities and targets with respect to attributes and attribute exposures, goal programming offers more flexibility. The applicability of multiple goal programming to the portfolio problem was recognized in an early stage. In the traditional mean-variance context, we have Lee (1972), Lee \& Lerro (1973), Kumar, Philipatos \& Ezell (1978), Lee \& Chesser (1980), Spronk (1981) and O'Leary \& O'Leary (1987). Aside from expected return and risk,

\footnotetext{
${ }^{7}$ Cf. Sorensen \& Thum's (1992) portfolio optimiser.

${ }^{8}$ One example is Arthur \& Ghandforoush (1987).
} 
some other attributes (notably dividend yield) are specified, but a truly multi-attribute representation is not pursued. But of course, the number of attributes could easily be extended. Multiple goal programming indeed has some attractive properties. It shows a close correspondence with decision making in practice, the goals are formulated as aspiration levels and there is always a solution for a well-defined problem (with a non-empty feasible region), even if some goals are conflicting. An important drawback of multiple goal programming, still, is its need for fairly detailed a priori information on the decision-maker's preferences.

Interactive programming methods, in contrast, neither require an explicit representation or specification of the decision-maker's preference function nor an explicit quantitative representation of the trade-offs among conflicting goals. By its nature, an interactive procedure progresses by seeking this information from the investor, removing the need to make the preference structure more explicit. For the investment problem as sketched in this paper, we propose Interactive Multiple Goal Programming (henceforth IMGP), as developed by Spronk (1981). In this procedure, the investor reduces the set of alternatives interactively and systematically, thus conditioning the quality of the remaining portfolios.

In broad lines, IMGP works as follows. Given a set of (investment) alternatives and a set of goal variables (attribute exposures), IMGP starts formulating minimum requirements for each of the goal variables, leaving a set of alternatives meeting the requirements. (For the ease of exposition, we assume that all goal variables are to be maximized.) This vector of minimum goal values is presented to the investor, together with a set of indicators of the potential improvements of these minimum goal values, within the set of feasible portfolios. In the first iteration, very low minimum goal values are chosen (viewed by the investor as absolute minimum conditions or even worse) in order to be sure that no potentially acceptable portfolios are excluded. Next, the investor has to indicate whether or not the portfolios meeting the minimum requirements are satisfactory. If so, he can choose one of these portfolios. If not, he has to indicate which of the minimum goal values should be increased. The constraint on the value of the corresponding goal variable is then reformulated.

On the basis of the resulting new vector of minimum goals values, a new set of indicators of the potential improvements of these values is calculated and presented to the investor. The investor has to indicate whether the shift in the indicated minimum goal value is outweighed by the shifts in the potentially attainable values of the other goal variables. If so, the investor 
has the opportunity to revise his earlier wishes with respect to the changed minimum goal value. If not, the change of the minimum goal value is accepted and the investor can continue to raise any of the other or even the same minimum goal value. Of course, by successively raising the minimum goal values from iteration to iteration, the set of feasible portfolios is gradually reduced by keeping only the portfolios that meet the higher standards. Each iteration produces indicators showing the 'price' of the higher standard, so the investor can evaluate the trade-offs between the goals (attributes).

The investor has several options. He can continue until the remaining set of feasible portfolios becomes very small. Another possibility is to select a suitable portfolio from the set of portfolios satisfying the minimum requirements. In this respect, IMGP produces at each iteration a set of non-dominated portfolios. Finally, a set of feasible portfolios satisfying the minimum conditions on the goal values can be subjected to a second analysis by the investor. In his decision context, the investor may wish (or need) some elbowroom, thus requiring more than just one portfolio. The procedure then offers adequate flexibility to incorporate other, hard to quantify, criteria into the decision making process. IMGP incorporates all the advantages of 'traditional' goal programming, while circumventing the unnecessary burden of obtaining a 'complete' picture of the investor's preference pattern. In our opinion, this approach offers the desired degree of flexibility to be fruitfully applied to the multi-attribute portfolio selection problem. By tuning the attribute exposures, a specific portfolio profile can be obtained that matches the investor's profile. In contrast to traditional approaches, the stages of portfolio analysis and portfolio selection are no longer treated separately but are integrated. The interactive method then is no optimiser, but can better be described as a 'combiniser': it allows systematic scanning of the set of feasible portfolios and the selection of an optimal portfolio via an interactive process. In the interactive decision process, a learning process is embedded. By scanning the feasible portfolios, the investor first gets a feeling for the tradeoffs that exist in the opportunity set between the exposures to the various attributes. Second, the investor can shape and adjust his preferences when confronted with the trade-offs between the attributes. It is in no way required that the investor performs the interactive process only once. He can explore the opportunity set in all dimensions, and is even advised to do so in order to get insight into the properties of the opportunity set at hand. Since the interactive procedure is path-independent, no desirable (feasible) alternatives can be missed, only insight can be gained. The proposed approach is illustrated by means of the results of our worked example in the next section. 


\section{Selecting a Portfolio: An Illustration}

Now we are able to present the results of an imaginary social responsible investor within our multi-criteria framework. We start with imposing the restriction that a maximum of $5 \%$ of the portfolio can be invested in one stock; this ensures some level of diversification. By applying the methodology of section 4 , Table 4 renders the starting iteration of our ten-factor model. The first row shows the attribute scores of the portfolio for which the community factor is maximised (at a level of 90.1). Because of the $5 \%$ restriction on the weights, the portfolio consists of the top-20 community stocks. From this first row we can also read that this portfolio brings a Total return of $17.6 \%$ and a Book to market value of 0.29 . The next rows of table 4 refer to the nine other portfolios where each time another factor is maximised. The bold diagonal entries of the table represent the maximum value of the corresponding attribute obtained over all portfolios. The potency matrix summarizes the attribute scores in the solution space after the first iteration. The "Max" row contains the maximum attainable attribute scores whereas the "Min" row shows the minimum scores.

Table 4: Starting Iteration; ten different portfolios

\begin{tabular}{|c|c|c|c|c|c|c|c|c|c|c|}
\hline & 1-Comm & $\begin{array}{c}2- \\
\text { Govern. }\end{array}$ & 3-Cust. & $\begin{array}{l}\text { 4-Emp.- } \\
\text { contr. } \\
\text { Rel. }\end{array}$ & $\begin{array}{l}\text { 5-Emp2- } \\
\text { labor } \\
\text { rights } \\
\end{array}$ & $\begin{array}{l}\text { 6-Emp3- } \\
\text { labor } \\
\text { care } \\
\end{array}$ & $\begin{array}{l}\text { 7-Env. - } \\
\text { P\&P }\end{array}$ & $\begin{array}{l}\text { 8-Env2- } \\
\text { F\&R }\end{array}$ & $\begin{array}{l}9-\mathrm{TR} \\
2000\end{array}$ & 10-BtMv \\
\hline 1-Community & 90.1 & 80.2 & 59.4 & 85.0 & 78.0 & 54.2 & 67.6 & 48.7 & 17.6 & 0.29 \\
\hline 2-Governance & 73.5 & 96.6 & 44.9 & 80.0 & 69.9 & 43.7 & 61.4 & 41.9 & 4.5 & 0.19 \\
\hline 3-Customers & 74.2 & 70.8 & 78.5 & 75.5 & 68.7 & 53.2 & 61.0 & 50.5 & 1.4 & 0.19 \\
\hline $\begin{array}{l}\text { 4-Employees- } \\
\text { contractual relations }\end{array}$ & 64.8 & 79.1 & 43.9 & 100.0 & 58.7 & 39.9 & 31.1 & 44.8 & 16.8 & 0.29 \\
\hline $\begin{array}{l}\text { 5-Employees-labor } \\
\text { rights }\end{array}$ & 78.4 & 75.1 & 55.8 & 80.7 & 86.6 & 55.3 & 74.8 & 48.5 & 19.8 & 0.19 \\
\hline 6-Employees-labor care & 69.5 & 69.3 & 55.0 & 79.6 & 69.8 & 67.8 & 61.7 & 53.7 & 10.6 & 0.23 \\
\hline $\begin{array}{l}\text { 7-Environment- } \\
\text { Principles\&policies }\end{array}$ & 67.6 & 70.0 & 54.3 & 68.3 & 70.5 & 54.7 & 93.1 & 53.4 & 1.5 & 0.34 \\
\hline $\begin{array}{l}\text { 8-Environment2- } \\
\text { Facts\&results }\end{array}$ & 66.8 & 73.2 & 41.6 & 87.5 & 64.3 & 46.5 & 66.2 & 76.7 & -3.9 & 0.19 \\
\hline 9-Total returns 2000 & 68.4 & 63.7 & 48.8 & 86.8 & 65.9 & 46.6 & 43.7 & 39.3 & 73.7 & 0.24 \\
\hline $\begin{array}{l}\text { 10-Book to Market } \\
\text { value2000 }\end{array}$ & 63.9 & 67.6 & 42.9 & 66.8 & 57.4 & 40.1 & 58.4 & 38.1 & -2.4 & 0.82 \\
\hline \multicolumn{11}{|l|}{ Potency Matrix } \\
\hline Max & 90.1 & 96.6 & 78.5 & 100.0 & 86.6 & 67.8 & 93.1 & 76.7 & 73.7 & 0.82 \\
\hline Min & 63.9 & 63.7 & 41.6 & 66.8 & 57.4 & 39.9 & 31.1 & 38.1 & -3.9 & 0.19 \\
\hline
\end{tabular}

Suppose now that our imaginary investor is primarily interested in the so-called 'growth stocks'. Economic theory indicates that stocks with relative high Book to Market ratios are undervalued and therefore promise some upward growth potential. For this reason we start the 
second iteration in which we impose an additional restriction, setting the minimum acceptable value for the Book to market value to 0.5. This narrows the space of feasible portfolios. The impact of the additional restriction on the other nine portfolios is summarized in the second column (labeled "1") of the potency matrix in Table 5.

Completely depending on our virtual investor's preferences a set of additional minimal values can be imposed on the optimization problem. In our application we choose to set seven consecutive additional restrictions on the sustainability scores. The only necessary check was whether the level of the attribute restriction was within the remaining feasible solution space as based on the potency matrix in Table 5. This resulted in the following additional portfolio requirements (with the average sample score between parentheses):

a) Customers relations $>=55$ (46)

b) Governance openness $>=75$ (70)

c) Community $>=75(66)$

d) Environmental Principles \& Policies $>=70$ (52)

e) Environment Facts \& Results $>=56(40)$

f) Employees Labour care $>=55$ (44)

g) Employees contractual relations $>=98(77)$

The attribute scores of the ten portfolios after iteration 8 is summarized in column 8 of Table 5; for detailed information on the attribute scores we refer to Appendix 2. Every portfolio reflects a combination of stocks that clearly scores above average on all indicated attributes. A final choice could be to buy the portfolio that maximised the return in the year 2000 . The resulting portfolio then has the following ten respective attribute scores (see row 9 of iteration 8 in Appendix 2): 76, 75, 55, 98, 71, 55, 71, 58, 21 and 51. So in economic terms we selected a portfolio with a return of $21 \%$, a book to market value of 0.51 and eight above-average sustainability scores.

Table 5: The potency matrix reflecting the solution space after every iteration.

\begin{tabular}{lcccccccccc}
\hline & Iteration: & Start & 1 & 2 & 3 & 4 & 5 & 6 & 7 & 8 \\
\hline 1-Community & Max & 90.1 & 88.3 & 88.3 & 88.3 & 88.3 & 88.0 & 87.0 & 86.7 & 78.5 \\
& Min & 63.9 & 63.9 & 63.9 & 63.9 & 75.0 & 75.0 & 75.0 & 75.0 & 75.6 \\
2-Governance & Max & 96.6 & 92.7 & 91.8 & 91.8 & 91.8 & 91.8 & 91.0 & 90.9 & 78.4 \\
& Min & 63.7 & 63.6 & 63.7 & 75.0 & 75.0 & 75.0 & 75.0 & 75.0 & 75.0 \\
3-Customers & Max & 78.5 & 74.0 & 74.0 & 72.9 & 72.9 & 72.9 & 71.2 & 71.1 & 57.0 \\
& Min & 41.6 & 41.6 & 55.0 & 55.0 & 55.0 & 55.0 & 55.0 & 55.0 & 55.0 \\
\hline
\end{tabular}




\begin{tabular}{|c|c|c|c|c|c|c|c|c|c|c|}
\hline $\begin{array}{l}\text { 4-Employees-contractual } \\
\text { relations }\end{array}$ & $\operatorname{Max}$ & 100.0 & 100.0 & 100.0 & 100.0 & 100.0 & 100.0 & 99.9 & 98.3 & 98.3 \\
\hline & Min & 66.8 & 66.7 & 69.9 & 69.9 & 69.9 & 69.9 & 75.6 & 75.6 & 98.0 \\
\hline \multirow[t]{2}{*}{ 5-Employees2-labor rights } & Max & 86.6 & 81.5 & 81.5 & 81.5 & 81.4 & 81.4 & 80.3 & 80.2 & 72.3 \\
\hline & Min & 57.4 & 57.4 & 57.4 & 57.4 & 65.6 & 65.6 & 66.8 & 68.6 & 69.4 \\
\hline 6-Employees3-labor care & Max & 67.8 & 64.1 & 64.1 & 64.0 & 63.9 & 63.9 & 63.3 & 63.3 & 55.5 \\
\hline 7-Environment- & Min & 39.9 & 39.9 & 43.1 & 43.6 & 43.6 & 44.1 & 48.5 & 55.0 & 55.0 \\
\hline Principles\&policies & Max & 93.1 & 91.6 & 91.4 & 90.9 & 89.4 & 89.4 & 89.1 & 88.3 & 71.3 \\
\hline \multirow{3}{*}{$\begin{array}{l}\text { 8-Environment2- } \\
\text { Facts\&results }\end{array}$} & Min & 31.1 & 31.1 & 31.1 & 31.1 & 44.7 & 70.0 & 70.0 & 70.0 & 70.0 \\
\hline & Max & 76.7 & 70.9 & 69.0 & 69.0 & 68.2 & 68.1 & 68.1 & 67.2 & 58.6 \\
\hline & Min & 38.1 & 38.1 & 38.1 & 38.1 & 38.0 & 45.4 & 56.0 & 56.0 & 56.0 \\
\hline 9-Total returns 2000 & Max & 73.3 & 54.7 & 52.4 & 48.2 & 47.7 & 45.1 & 42.1 & 41.0 & 21.1 \\
\hline \multirow{3}{*}{$\begin{array}{l}10-\text { Book to Market } \\
\text { value } 2000\end{array}$} & Min & -3.9 & -3.9 & -3.9 & -3.9 & -3.9 & -3.9 & -3.9 & -3.9 & 11.2 \\
\hline & Max & 0.82 & 0.82 & 0.78 & 0.76 & 0.76 & 0.76 & 0.70 & 0.67 & 0.51 \\
\hline & Min & 0.19 & 0.50 & 0.50 & 0.50 & 0.50 & 0.50 & 0.50 & 0.50 & 0.50 \\
\hline
\end{tabular}

Finally, Table 5 shows that the eight iterations have narrowed the solution space considerably.

Column 8, representing the final iteration, clearly indicates the restrictions on the factors 3 customers, 4-employees contractual relations, 6-employees labour care, 7-environment P\&P and 10 the book to market value. Total returns is the only attribute that shows considerable room for improvement. Our investor can now select one of the 10 portfolios, or any linear combination of them. Each choice will satisfy the constraints that have been added in the interactive process.

\section{Summary and conclusions}

In theory as well as in practice there is increasing interest in the issues of sustainability and social responsibility. Given this development the question arises how these issues can be incorporated in the investment decision process. In this paper we presented a complete framework for selecting a portfolio of socially responsible investments. Characteristic ingredients of the framework are: (i) a multi-dimensional description of the investment opportunities (together with the prior stage of data reduction), (ii) the measurement of attributes on the portfolio level, and (iii) a flexible procedure supporting the decision-maker in evaluating the trade-offs between the selected portfolio attributes and choosing a final portfolio that satisfies his goals and constraints. The multi-criteria character is inherent to the studied decision problem. In addition we impose the restriction that the procedure should not require detailed a priori preference information from the decision-maker. In particular, the investor should be able to evaluate the attribute trade-offs offered by the opportunity set so 
that he can shape his preferences in this respect. For satisfying this high degree of flexibility we propose implementing interactive multiple goal programming.

We illustrated the framework with a real-life example. For some hypothetical investor we outlined the decision process and showed how the feasible set of portfolios is reduced. We acknowledge that there are alternative ways to fill in the framework. However the outstanding features of the proposed approach are (i) it offers insight into the trade-offs between the attributes considered, (ii) traditional one-step portfolio selection is substituted by combining the stages of portfolio analysis and selection, which allows the decision-maker to gradually reduce the set of feasible portfolios on the basis of the observed trade-offs, and (iii) the stepwise decision-process together with the explicit attributes allows for easier communication of the decision process and the final results.

Some important issues are left for future research. For example, the data reduction process as briefly mentioned in section 3. Questionnaires on sustainability typically consider many aspects and as a result information on sustainability performance is multifarious. The question arises how the abundant data can be summarized and compressed in terms of only a limited number of attributes. It is desirable that attributes are not redundant and that the selected attributes can explain most of the variation in the data set. Another issue is portfolio diversity. The scores on the sustainability attributes are evaluated on the aggregate portfolio level. The portfolio score is a weighted average of the scores of the individual securities comprised in that portfolio. Given some sustainability attribute, the specific score of the portfolio can be generated by a diversity of security attribute scores. So the dispersion in security scores underlying a portfolio attribute score can be very large or very small. Although we assume that the attributes are measured on (at least) an interval scale, it is questionable whether an investor would be indifferent between a large and only a small degree of underlying dispersion in the scores. When the assumed substitutability between attribute scores is limited, additional attributes can be incorporated in the decision process, indicating the spread of underlying attribute scores. 


\section{References}

Arthur, J.L. \& P. Ghandforoush, 1987, Subjectivity and Portfolio Optimization, in: K.D. Lawrence, J.B. Guerard \& G.R. Reeves (eds), Advances in Mathematical Programming and Financial Planning, Volume 1, JAI Press, Greenwich, Conn., pp. 171-186

Deaton, A. \& J. Muellbauer, 1980, Economics and Consumer Behavior, Cambridge University Press, Cambridge UK

Elton, E.J. \& M.J. Gruber, 1995, Modern Portfolio Theory and Investment Analysis, John Wiley \& Sons, New York NY

Fama, E.F., 1991, Efficient Capital Markets: II, The Journal of Finance 46/5, Dec, pp.15751617

Fama, E.F. \& K.R. French, 1992, The Cross-Section of Expected Stock Returns, The Journal of Finance 47/2, June, pp. 427-465

Fama, E.F. \& K.R. French, 1993, Common Risk Factors in the Returns on Stocks and Bonds, Journal of Financial Economics 33, pp. 3-56

Hallerbach, W.G. \& J. Spronk, 1997, A Multi-Dimensional Framework for Portfolio Management, in: M.H. Karwan, J. Spronk \& J. Wallenius (eds), Essays in Decision Making, Springer Verlag, Berlin, pp. 275-293

Hawawini, G. \& D.B. Keim, 1995, On the Predictability of Common Stock Returns: WorldWide Evidence, in: R.A. Jarrow, V. Maksimovich \& W.T. Ziemba (eds), Finance, in the Handbook Series, North-Holland

Jensen, M.C., 2001, Value Maximization, Stakeholder Theory, and the Corporate Objective Function, Journal of Applied Corporate Finance 14/3, Fall, pp. 8-21

Lakonishok, J., A. Schleifer \& R.W. Vishny, 1994, Contrarian Investment, Extrapolation, and Risk, The Journal of Finance 49/5, Dec, pp. 1541-1578

Lancaster, K.J., 1966, A New Approach to Consumer Theory, Journal of Political Economy 74, April, pp. 132-157

Kumar, P.C., G.C. Philipatos \& J.R. Ezell, 1978, Goal Programming and the Selection of Portfolios by Dual Purpose Funds, The Journal of Finance 33/1, March, pp. 303-310

Lee, S.M., 1972, Goal Programming for Decision Analysis, Auerbach, Philadelphia

Lee, S.M. \& D.L. Chesser, 1980, Goal Programming for Portfolio Selection, The Journal of Portfolio Management Spring, pp. 22-26

Lee, S.M. \& A.J. Lerro, 1973, Optimizing the Portfolio Selection for Mutual Funds, The Journal of Finance 28/5, Dec, pp. 1087-1101

Markowitz, H.M., 1959, Portfolio Selection: Efficient Diversification of Investment, John Wiley, New York NY

O'Leary, J.H. \& D.E. O'Leary, 1987, A Multiple Goal Approach to the Choice of Pension Fund Management, in: K.D. Lawrence, J.B. Guerard \& G.R. Reeves (eds), Advances in Mathematical Programming and Financial Planning, Volume 1, JAI Press, Greenwich, Conn., pp. 187-195

Sorensen, E.H. \& C.Y. Thum, 1992, The Use and Misuse of Value Investing, Financial Analysts Journal March-April, pp. 51-58

Spronk, J., 1981, Interactive Multiple Goal Programming: Applications to Financial Planning, Martinus Nijhoff, Boston 


\section{Appendix 1}

Research companies of the SiRi Group (www:sirigroup.org)

AReSE

Avanzi, s.r.1

CaringCompany AB

Centre Info SA

Fundación Ecología y Desarrollo

KLD Research \& Analytics, Inc.

Michael Jantzi Research Associates

Pensions \& Investment Research Consultants Ltd

Scoris GmbH

STOCK at STAKE SA

Sustainable Investment Research Institute P/L

Triodos Research BV
SA France

Italy

Sweden

Switzerland

Spain

United States

Canada

United Kingdom

Germany

Belgium

Australia

The Netherlands 


\section{Appendix 2}

Iteration 8:

Employees-

contractual

relations $>=98$

4- 5- 6- 10-

Empl. Empl. Empl. 7-Env. -Env- 9-Total BtMt

1-Com.2-Gov. 3-Cust.C R LR LC P\&P F\&R returns value

\begin{tabular}{|c|c|c|c|c|c|c|c|c|c|c|}
\hline 1-Community & $\underline{79}$ & 77 & 55 & 98 & 72 & 55 & 70 & 56 & 15.7 & 0.50 \\
\hline 2-Governance & 78 & $\underline{78}$ & 55 & 98 & 72 & 55 & 70 & 56 & 13.1 & 0.50 \\
\hline $\begin{array}{l}\text { 3-Customers } \\
\text { 4-Empl. } \\
\text { contractual }\end{array}$ & 78 & 75 & $\underline{57}$ & 98 & 71 & 55 & 70 & 56 & 14.9 & 0.50 \\
\hline $\begin{array}{l}\text { relations } \\
\text { 5-Employees- }\end{array}$ & 76 & 75 & 55 & $\underline{98}$ & 71 & 55 & 70 & 56 & 12.8 & 0.50 \\
\hline $\begin{array}{l}\text { labor rights } \\
6 \text {-Employees- }\end{array}$ & 77 & 75 & 55 & 98 & $\underline{72}$ & 55 & 70 & 56 & 12.8 & 0.50 \\
\hline labor care & 76 & 75 & 55 & 98 & 71 & $\underline{55}$ & 70 & 56 & 12.3 & 0.50 \\
\hline $\begin{array}{l}\text { 7-Env.P.\&P } \\
\text { 8-Env.- }\end{array}$ & 76 & 75 & 55 & 98 & 71 & 55 & $\underline{71}$ & 56 & 11.2 & 0.50 \\
\hline Facts\&results & 76 & 75 & 55 & 98 & 69 & 55 & 70 & $\underline{59}$ & 12.8 & 0.50 \\
\hline 9-Total returns & 76 & 75 & 55 & 98 & 71 & 55 & 70 & 56 & $\underline{21.1}$ & 0.51 \\
\hline 10-BtMvalue & 76 & 75 & 55 & 98 & 71 & 55 & 70 & 56 & 12.7 & 0.51 \\
\hline
\end{tabular}




\section{Publications in the Report Series Research ${ }^{*}$ in Management}

ERIM Research Program: "Finance and Accounting"

2002

A Stochastic Dominance Approach to Spanning

Thierry Post

ERS-2002-01-F\&A

Testing for Third-Order Stochastic Dominance with Diversification Possibilities

Thierry Post

ERS-2002-02-F\&A

Towards a Transaction Cost Theory of Management Control

Roland F. Speklé

ERS-2002-06-F\&A

Modeling the Conditional Covariance between Stock and Bond Returns: A Multivariate GARCH Approach Peter De Goeij \& Wessel Marquering

ERS-2002-11-F\&A

An Empirical Comparison of Default Swap Pricing Models

Patrick Houweling \& Ton Vorst

ERS-2002-23-F\&A

Relative Distress and Return Distribution Characteristics of Japanese stocks, a Fuzzy-Probabilistic Approach Willem-Max van den Bergh, Onno Steenbeek \& Jan van den Berg ERS-2002-29-F\&A

Does Risk Seeking Drive Asset Prices? A Stochastic Dominance Analysis of Aggregate Investor Preferences Thierry Post \& Haim Levy

ERS-2002-50-F\&A

Reinventing The Hierarchy, The Case Of The Shell Chemicals Carve-Out Michel A. van den Bogaard, Roland F. Speklé

ERS-2002-52-F\&A

A Framework For Managing A Portfolio Of Socially Responsible Investments Winfried Hallerbach, Haikun Ning, Aloy Soppe, Jaap Spronk ERS-2002-54-F\&A

\footnotetext{
A complete overview of the ERIM Report Series Research in Management: http://www.ers.erim.eur.nl

ERIM Research Programs:

LIS Business Processes, Logistics and Information Systems

ORG Organizing for Performance

MKT Marketing

F\&A Finance and Accounting

STR Strategy and Entrepreneurship
} 